\title{
Magical or Monstrous? Hybridity in Social Housing Governance
}

Anita Blessing, University of Amsterdam, March, 2010

\section{Introduction}

Contemporary Dutch and Australian social housing systems, while very different, are similarly marked by legal tensions over the role of the non-profit form. In Australia, a new government affordable housing scheme built around a central role for a small nonprofit sector recently tripped on its own shoelaces. Non-profit participants, already up and running with projects, received a warning from the Tax Office. They faced losing their tax-exempt charitable status on the grounds that the scheme assists moderate-income households as well as those in poverty. While temporary legislation is now in place to support non-profit involvement, ongoing legal foundations for the scheme have yet to be developed. In the Netherlands, non-profit associations collectively form a large social housing sector, channelling profits from commercial real-estate activities towards social ends. Over recent years, their role has come under fire on the grounds that state support may advantage them in their commercial ventures, thereby undermining the 'level playing field' enshrined within EU Competition Policy. With the long term implications of this controversy still unclear, some foresee "a long period of uncertainty” (Priemus, 2008, p81).

Although tensions between social and commercial housing agendas are by no means unique to the Dutch and Australian contexts, the two non-profit sectors are chosen here for comparison on the basis of the contrasting sets of developmental pressures they now face. As the Australian government restructures public services, a small non-profit 
housing sector is coming into favour as a means of integrating social and commercial housing activities. This approach aims to boost private investment in social projects and minimise negative stigma. In contrast, the comparatively mature Dutch social housing sector, internationally admired for its integration of social and commercial interests via the non-profit form, is positioned as transgressing a boundary between the two. Juxtaposed, the two cases highlight the challenges in both creating legal scope for new non-profit activities and in maintaining this scope as non-profit housing sectors mature and policy environments change. Both sectors face legal uncertainty, with potential implications for future planning and development.

While the internal capacity of non-profits to meet housing needs is a common point of debate, this study explores the legal parameters within which they work as equally important in shaping social housing outcomes. The following research questions are addressed with regard to both Dutch and Australian policy contexts.

How is scope for the entrepreneurial activities of non-profits defined within housing policy and within relevant economic legislation?

How are these arrangements changing and what accounts for these changes?

In exploring the nature of institutional change, new opportunities and challenges for nonprofits emerging out of the current context of economic crisis beg consideration. However, crisis measures departing from the status quo are given little attention here. Rather, the relevance of the economic crisis to this discussion lies in the possibility for rupture with the past and for reform of institutional arrangements that no longer reflect the current state of play. 
A related aim of this paper is to further develop the conceptual basis for research into what is alternately referred to as the 'non-profit', 'third', 'community', or 'voluntary' sector. With the above terms revealing little about the role of contemporary nongovernment social housing organisations, the concept of hybridity is explored as an alternative approach. Within a governance context, the term 'hybrid' has been applied to both entities combining social and commercial tasks, and to the relationships within which they work (Priemus, 1995), (Brandsen et al, 2005b p6), (Salet and Schuiling, 2006). Here, hybridity is used as a lens through which the research questions are examined.

Part One of the paper develops the concept of hybridity as an approach to social housing governance and explores theoretical perspectives on the development of social housing markets. Part Two describes examples of Dutch and Australian non-profit housing associations on the 'cutting edge' of national trajectories of development. It then compares sets of institutional conditions for the more entrepreneurial activities of non-

profits set out within housing policy and within economic law, revealing a legal basis for discord. Part Three uses the concept of hybridity to explore the origins of discord over non-profit housing activities. A concluding section draws on the theories introduced in Part One.

\section{Part One: Hybridity as a governance concept}

Characteristically used in biology, the label 'hybrid' is now applied to an increasing range of heterogeneous products, systems and entities, from cars to musical genres to forms of governance. Brandsen et al. define hybridity within a governance context in terms of organizations and ways of working that cross-cut "state, market and civil society" (Brandsen et al, 2005a p. 6) and involve the mixing of ideal types, cultures, coordination mechanisms, rationalities, or action logics. 
How then, does hybridity pertain to social housing governance? Here, 'social housing' is broadly defined as rental housing provided at below market rates to a government-defined social mandate. The terms 'hybrid', and 'cross-sectoral' are limited to arrangements across public and private sectors that span at least a decade, or are ongoing. For example, a non-profit or for-profit private entity might develop, manage or invest in housing according to a time-limited or ongoing social mandate in return for government support.

At the centre of these hybrid arrangements are individual social housing providers that internalise ongoing social responsibility through non-profit status. In both Dutch and Australian contexts, this entails a legal constraint prohibiting distribution of economic surplus to owners. It also imparts ongoing public accountability. At the organisational level, the classification 'hybrid' thus pertains to entities that "combine public and private tasks in a more or less autonomous and durable way” (Salet and Schuiling, 2006 p. 3).

In Australia, non-profit, non-government housing providers are referred to as 'community housing associations', and are part of the 'community sector'. While this term captures local ties, it problematically excludes both government and for-profit housing providers from the 'community'. The internationally used terms 'non-profit' and 'not-for-profit' fail to capture the increasingly entrepreneurial nature of social housing provision, which is often oriented towards both social and commercial gains. 'Third sector' differentiates private non-profit actors from their public and for-profit counterparts, but says little about the cross-sectoral responsibilities that define their work. 'Voluntary' is a popular yet inappropriate descriptor of a sector increasingly staffed by paid professionals.

Four symbolic interpretations of hybridity

Over time, the concept of hybridity has gathered layers of meaning through use across 
diverse contexts. A distinction emerges between different perspectives on hybrid forms according to whether they are viewed as having their own distinct identities $(A+B=C)$, or as combinations of their parent components $(\mathrm{A}+\mathrm{B}=\mathrm{AB})$. Salet and Schuiling explore this distinction through analysis of the institutional conditions for hybrid housing provision. By comparing different sets of conditions within socio-cultural, political, economic and legal institutional environments, they uncover a form of 'discord' between them. While socio-cultural and political institutions 'recognize' hybrid identity, economic and legal domains, which draw strong distinctions between sectors and coordination mechanisms, are more likely to view hybrid organisations in terms of their component parts (see Salet and Schuiling, 2006).

For Brandsen et al, this tendency to define hybrid forms according to their component parts poses a conceptual barrier to understanding them (2005a and b). To illustrate this problem, they delve into mythology and come up with the Griffin, calling it a "fantastic creature that can only be described in terms of its constituent parts, which by implication means that it has no clearly defined identity of its own” (Brandsen et al, 2005b, p. 759). To differ with Brandsen et al, the example of the Griffin positions hybrid identity as strong and distinct. As a blend of the eagle, king of the air, and the lion, king of the land, the Griffin spans Heaven and Earth. Signifying divine power, it has been used over time to herald powerful regimes (Eason, 2007). Thus, its meaning far transcends the sum of its parts.

Hybrid identity resonates with equal power within a governance context. Following Brandsen et al's foray into mythology, this contribution identifies four popular interpretations or 'frames' of hybridity that help shape institutional conditions for nonprofit housing provision. These interpretations include; hybrids as links between cultures, the concept of hybrid vigour, hybridity as a transgression of binary order and hybridity as 
a state of transformation. The aim is to use these frames to compare scope for the activities of non-profits from two different perspectives: housing policy and economic law.

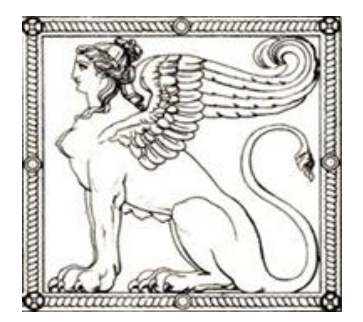

Hybrids as links between cultures

A first interpretation of hybridity arises from the foreign origins of several hybrid creatures in Ancient Greek mythology, including the Sphinx and the Chimera (see Burr, 1993). It positions hybrids as cross-cultural icons or links between cultures. This view of hybridity often enters policy discourses as a justification for shifts away from direct government provision of social services and towards governance of cross-sectoral arrangements. It is used to emphasize the socio-cultural 'grassroots' value attached to the non-profit sector as a voice for communities, helping elicit a government response to social needs. Here, hybrid identity is conceived of in terms of a cross-pollinating role of institutional mediation, connecting government with local networks, enlisting for-profit entities in social causes, facilitating the transfer of information and skills across sectors and laying the foundations for ongoing relationships. Brandsen et al acknowledge this element of hybridity, observing that, "it is possible that in bouncing between different environments, hybrid organisations may serve to transfer elements between those environments” (Brandsen et al, 2005a, p. 8). 


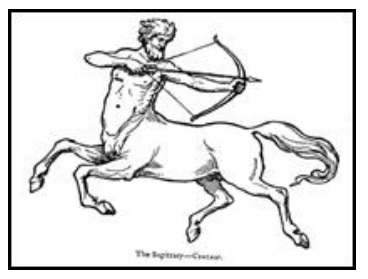

Hybrid vigour

The concept of hybrid vigour or heterosis, which describes the inherent strength of hybrid organisms, provides a compelling ideological frame underpinned by stories of powerful and magical mythological hybrids like the Griffin and the Centaur (see Burr, 1993 p. 60). The prospect of obtaining a better or stronger individual by combining the virtues of its parents lends itself well to a governance context, with hybrid organisations often idealised as super-blends of ethical drive, professional acumen and practical know-how. Here, the hybrid form is acknowledged as possessing a distinct, even magical identity. Like the notion of hybrids as links between cultures, the idea of hybrid vigour permeates the rhetoric surrounding the 'slimming down' of public services, and the resulting shift towards cross sectoral 'governance' of social housing outcomes through the non-profit sector. The positive framing of hybrid governance in terms of innovative new partnerships clustered around perceived legal, economic and 'moral' advantages of the hybrid form, and leading to 'institutional complementarity', helps to legitimatise the minimisation of the state (see Rhodes, 1996 pp. 653 and 667).

As evidenced in biology, with some cross-breeds proving to be infertile or ill-equipped for survival, hybrids are by no means inherently powerful. In governance, the crosssectoral action that is characteristic of hybrid organizations carries multiple risks, and this 'vulnerability' is the flip-side to hybrid vigour. Salet and Schuiling characterise the position of hybrid organisations in between the institutions of the market and the state as “extremely vulnerable in times of social change” (2006, p. 2). Forced to simultaneously straddle different sets of rules and draw on diverse sources of support, hybrids must also invest in multiple forms of accountability. Hybrid relationships are rendered equally 
vulnerable by cultural clashes, such as differing goals, and varying ways of measuring capacity.

Observing that notions of state power, authority and democracy are often presented as outmoded impediments to cross-sectoral action, Salet highlights additional risks of hybrid governance, in the form of "volatile horizontalism or gated partnerships" resting on illusions of "instant legitimacy” (Salet and Schuiling, 2006 p. 9), see also (Rhodes, 1996 p. 662).

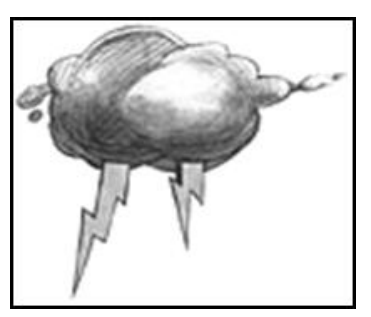

Hybridity as a state of transgression

A further aspect of hybridity visible in tensions between policy and law is rooted in the etymology of the term. Derived from the Latin word hybridia (itself from the Greek hubris), and denoting "the offspring of a tame sow and wild boar" (two progenitors amusingly reminiscent of the state and the market), the term 'hybrid' may be interpreted as an "outrageous miscegenation" (The Concise Oxford Dictionary, 2001 p. 695). In an economic context premised upon the dichotomisation of market and state, the flexibility of hybrid status, for example; the potential to blend 'action logics' and combine social and commercial functions, may be read as duplicitous, unjust, or threatening. Thus viewed, hybrid organisations are positioned as transgressions of the binary opposition of state and market. This frame of 'institutional discord', which limits hybrid identity to its component parts, places the actions of hybrid housing providers under the political spotlight. 


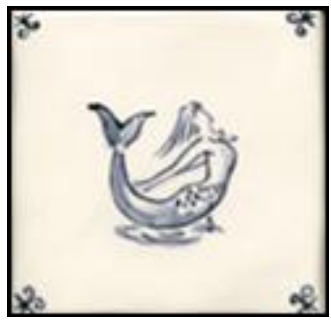

Hybridity as a state of transformation

A final reading of hybridity with both mythological roots and resonance within a governance context is transformation. A mermaid, for example, may shape-shift as she negotiates water and land (Bell, 1991 p.322). Invoking Ovid’s Metamorphosis, Brandsen et al associate hybrid governance with ongoing transformation and with the blurring of sectoral boundaries (2005b p749.). Ascribing this volatility to the shifting of funds and responsibilities across sectors (Brandsen et al, 2005b p753), they argue that in the absence of a clear understanding of hybrid identity, hybrid organisations may be best characterised in terms of the strategies they employ to retain their integrity as they adapt to change (p759). For non-profit housing providers, adaptation may take the form of organisational change in response to stricter enforcement of existing institutional requirements, or as a means of fulfilling new institutional requirements that emerge as social norms evolve.

While transformation may be a valid lens through which to view the hybrid form, the relationship between organisational flexibility and integrity over time is difficult to measure. Furthermore, positioning volatility as an inherent characteristic of hybridity may obscure the fact that some of the strongest hybrid forms and relationships have emerged gradually, within relatively stable institutional environments. Viewing transformation as inherent to hybridity also raises the risk of overlooking the causal factors driving change. 
Table 1. Four frames of hybridity in social housing governance

\begin{tabular}{|c|c|}
\hline $\begin{array}{l}\text { Frame: Hybrids as links between cultures } \\
\text { Indicator: institutional mediation e.g. } \\
\text { - linking government to grassroots } \\
\text { issues } \\
\text { - } \begin{array}{l}\text { cross pollination of knowledge, } \\
\text { skills and ways of working across } \\
\text { sectors }\end{array} \\
\text { - laying foundations for on-going } \\
\text { cross-sectoral relationships }\end{array}$ & $\begin{array}{l}\text { Frame: Hybrid vigour } \\
\text { Indicator: institutional complementarity e.g. } \\
\text { - } \quad \text { innovative cross-sectoral blends of } \\
\text { qualities and powers } \\
\text { - } \quad \text { complementary cross sectoral } \\
\text { partnerships } \\
\text { - } \quad \begin{array}{l}\text { accumulation of skills, assets and } \\
\text { resources within the non-profit } \\
\text { sector }\end{array}\end{array}$ \\
\hline $\begin{array}{l}\text { Frame: Hybridity as a transgression } \\
\text { Indicator: institutional discord e.g. } \\
\text { - controversy over the commercial } \\
\text { activities of non-profits } \\
\text { - controversy over non-profits' use } \\
\text { of state or charitable funds } \\
\text { - controversy over the legal status } \\
\text { of non-profits (public, private, } \\
\text { hybrid) }\end{array}$ & $\begin{array}{l}\text { Frame: Hybridity as a state of } \\
\text { transformation } \\
\text { Indicator: institutional and/or organisational } \\
\text { change e.g. } \\
\text { - organisational restructuring } \\
\text { - changes in housing policy } \\
\text { - tightening or relaxation of } \\
\text { economic legal constraints }\end{array}$ \\
\hline
\end{tabular}

Theoretical perspectives on the development of social housing systems

Two comparative studies of the long-term development of social housing systems; Harloe's The People's Home (1995) and Kemeny's From Public Housing to the Social Market (1995) been drawn upon in recent years for insights into the dynamics of nonprofit housing provision (see for example Gruis and Priemus, 2008). While neither work specifically addresses the (non-government) non-profit sector, both focus on tensions between social and commercial interests in housing markets, which have commanded 
increasing attention as the role of non-profits has developed.

Harloe's study of social housing systems in six countries positions social housing as influenced by national institutional environments, but ultimately defined by housing market dynamics. He differentiates between the mass model of social housing, characterised by broad access to housing assistance and the residual model, which rations assistance to those in 'highest need' (Harloe, 1995). For Harloe, the mass model poses "a challenge to core capitalist interests” (p. 538), manifesting only in instances where the market fails; or where a lack of adequate housing is impeding other economic activity (pp. 524 and 546). On this basis, he posits an international trend towards the residual model of social housing.

While Harloe's main emphasis is on the effects of markets on social housing systems, Kemeny's study of rental policies in seven countries flips the lens to focus on the potential for housing policy to shape housing markets. Kemeny differentiates between the unitary rental market, characterised by integration of cost-renting to compete with for-profit forms, and the (typically Anglo Saxon) dualist market, involving government co-option and residualisation of cost rental to prevent it from competing with for-profit actors (Kemeny, 1995 pp. 11 and 179). In a later work, Kemeny et al further distinguish between the unitary rental market, and the integrated rental market, wherein competition between cost and profit rental has led to the cost-rental sector becoming strong enough to set norms for dwelling standards and create a form of 'tenure neutrality' (Kemeny et al, 2005). For Kemeny, the different 'structurings' of cost and profit rental forms in housing markets are strategic.

The two similar perspectives are differentiated by different views of housing markets. While Harloe acknowledges that the market is a construct, he assumes the continuing 
predominance of a particular model that is profit-driven, attuned to individualistic housing needs and based on a 'level playing field', or a single set of rules for fair competition. Boundaries between social and commercial housing are in place to prevent distortion of supply and demand signals. Kemeny takes a broader view of capitalism and sees potential for various international iterations, including pursuit of the integrated rental market as an overarching strategy (Kemeny et al, 2005, p870). His 'level playing field', (the integrated market), is a state of hybrid vigour in which the non-profit rental sector has reached a sufficient scale and level of maturity to compete with for-profit forms of rental, thus encouraging the best possible performance from each side. While the ultimate aim of such a market is to do away with state subsidies, support is required to bring the social market to maturity (Kemeny, 1995 p. 164). Thus, the playing-field is founded on two sets of rules.

\section{Expected findings}

The theoretical perspectives set out above are applied to the Australian and Dutch policy contexts with two main expectations. First, and in line with the notion that hybrid identity is easier to reconcile with social or political institutional requirements than with economic or legal imperatives, it may be anticipated that the frames of 'links between cultures', and 'hybrid vigour' will emerge within housing policy discourses, which embrace the nonprofit form as pathway to institutional mediation and complementarity. Economic and legal institutional domains are more likely to frame hybridity as a transgression, requiring transformation. Secondly, in line with Kemeny's and Harloe's studies, it is expected that the cases will reveal tensions between social and commercial activities in housing markets as instrumental in shaping the development trajectories of social housing systems, and the role of non-profits within them. 


\section{Part Two: Non-profit housing provision in Australia and the Netherlands}

\section{Australia}

In Australia, the main form of social housing is public housing provided by state governments, and funded nationally. This makes up around $5 \%$ of dwellings. An increasing number of households rent on the private market, which comprises around $21 \%$ of total housing stock (National Shelter, 2007). Recent statistics show that $40 \%$ of these households remain in the rental market for a period of 10 years or more (Beer et al, 2007 p. 12). Homeownership is the dominant form of tenure.

Non-profit housing providers are referred to as 'community housing associations'. While the sector provides for some moderate-income households, over $75 \%$ of tenants receive a government benefit. Most Australian community housing providers target their services towards one or more specific needs groups, such as elderly people, those with a disability or homeless people (CFHA, 2007b). They employ professionals, but may also be reliant upon labour and advice provided on a voluntary basis. Australia's relatively small community housing sector is often counted as part of its public housing stock. The Community Housing Federation of Australia represents over 2,000 organisations across the country, with an estimated 68,000 dwellings. Community housing associations tend to be small, with only 5\% holding more than 200 dwellings. While $53 \%$ hold title to some or all of their properties (CFHA, 2007b), others manage government assets.

While growth and commercial risk-taking are by no means characteristic of the Australian non-profit sector, Government, in response to plummeting housing affordability, has begun to encourage both practices through development of a culture of social-entrepreneurship. Community Housing Ltd (CHL) exemplifies this trajectory of development. Founded in 1994 with a government grant, CHL now designs, builds, 
manages and rents homes in several Australian states, making use of donated land, privately-sourced loans and government funding. In keeping with its vision of 'providing affordable and sustainable housing for all' it also has international development projects active in Timor Leste and Chile. With around 110 employees and a rapidly growing asset base of over 2000 properties (CHL, 2009), CHL houses a range of different groups sourcing around two thirds of the capital cost of its housing from government grants. Through vertical integration of the housing production chain, it avoids builder and developer costs. These advantages allow CHL to offer favourable terms to private investors and to provide secure rental housing at below-market rates (Werden, 2008). The company's approach is defined by an emphasis within its projects on job creation, community development and environmental efficiency.

CHL rivals for-profits as one of Australia's fastest growing businesses and is now pursuing relationships with major banks and funds (CHL, 2009). Although its eligibility criteria are aligned with the state public housing system to target low-income households, CHL also accepts some applications from 'key workers' or moderate-income households that are priced out of their communities. While CHL does not carry out purely commercial activities, its approach to marketing and development is seen as narrowing the gap between the community sector and for-profit real-estate developers. From a Government perspective, CHL's success in growing its asset base while simultaneously maintaining links with vulnerable community groups embodies the ideals of both 'links between cultures', and 'hybrid vigour'.

Institutional conditions for social entrepreneurship

Political scope for CHL's role as a provider of 'affordable' rental housing is set out within both state and Federal housing policy programs. It is one of a small number of housing associations designated by state governments as 'growth providers', to lead the 
sector's foray into affordable housing development. Federal support for this approach comes in the form of the National Rental Affordability Scheme (NRAS); a major new housing supply initiative based on US models such as the Low-Income Housing Tax Credit Scheme. Through competitive tender open to both non-profit and for-profit developers, the NRAS allocates project-based financial incentives over a ten-year period for each new rental dwelling made available to low and moderate-income households. Target groups include key-workers, people with a disability, Indigenous Australians and older people. In order to encourage non-profit participation, a sector capacity-building program has been developed and portions of incentives that are usually paid annually are made available to non-profits upfront. (FAHCSIA, 2008, 2009).

While housing policy scopes out an entrepreneurial foray into mainstream housing activities for non-profits like CHL, other rules of the game fall under taxation law, which aims to ensure that state and philanthropic support flow to worthy causes. When it comes to social housing, tax law is not unlike competition policy in that it keeps state support off the 'playing field' of commercial real estate development. Under tax law, crucial financial supports for non-profit activities are tied to charitable or Public Benefit Institution (PBI) status. They include exemption from Goods and Services Tax and Fringe Benefit Tax, with the latter helping non-profits to retain staff in an often underresourced sector (QCHC, 2008). Tax-deductibility of donations received is a further benefit. As a registered charity, CHL must have as its 'sole purpose' a mission deemed charitable by the Australian Tax Office. While the applicable mission for community housing providers is 'the relief of poverty', there is no precise definition of poverty for non-profits to work from (CFHA, 2009). Despite some tolerance for a low-level of 'incidental' commercial activities that further a charitable mission, undertaking commercial activities for fundraising is specifically flagged as 'not a charitable purpose' (ATO, 2009). 
In summary, there is a significant mismatch between scope for non-profit activities outlined within new Australian affordable housing policy, which focuses on prevention of exclusion from the housing market due to low-affordability or discrimination, and within taxation law, which limits non-profits to addressing exclusion from the housing market after the fact, due to poverty. This constitutes a legal basis for ongoing tensions between social and commercial interests in housing markets.

\section{The Netherlands}

Within the context of a general shortage of housing that meets contemporary needs Dutch social housing comprises a relatively large share of around $35 \%$ of housing stock. Homeownership stands at $54 \%$, with $11 \%$ of total dwellings in the for-profit private rental market (CECODHAS, 2009). While housing associations are private nongovernment organisations, social housing remains a 'co-production', with central government outlining broad strategic directions and modes of support and regulation. Housing associations periodically negotiate housing production and land supply with local municipalities (VROM, 2009).

As owners of social housing and other assets, the approximately 450 Dutch housing associations (AEDES, 2009) are in a strong financial position that supports an entrepreneurial approach to tasks such as providing rental housing at $30-45 \%$ below market rates and undertaking urban renewal projects (Priemus, 2006). Over the years, housing associations have enjoyed access to low-cost land and significant exemptions from taxes paid by for-profits. Some important collective resources that remain include two funds: the Social Housing Guarantee Fund, which provides cheap credit and the Central Fund for Housing, for emergency finance. AEDES, an 'umbrella' organisation, 
represents the sector in external negotiations and undertakes research. The independent, government established SEV runs long-term experimental programs to encourage innovation in social housing.

As the owner and manager of around 82,500 homes and constructing a further 2,600 dwellings each year, Ymere, a former municipal housing provider and the product of a recent merger, is one of the largest Dutch housing associations. As a private non-profit developer and manager of both social and market rate real-estate products, Ymere typifies the hybrid role of the sector. The organisation's scale, its substantial asset base, its sectorspecific resources and the broad social mandate within which it works equip it to raise capital and shoulder risks. Through the development of market-rate housing and commercial premises for sale and rental, it builds capacity to provide social rental housing and to carry out other potentially loss-making social activities. Ymere integrates social and commercial activities both through its 'liquid' operations, via the flow of commercially-derived profits back into social and operational functions, and through the spatial co-location of social and market rate housing in order to prevent stigmatisation and to meet demand for home-ownership (Ymere, 2009).

From the perspective of government seeking to meet housing needs externally, the combination of ethical drive and professional acumen that characterises Ymere's role are highly suggestive of 'hybrid vigour'. What better vehicle for social housing provision than an organisation combining economy of scale, diversity of function and financial independence with a willingness to take on challenges that for-profits might avoid? Yet from the perspective of commercial operators in the real-estate market, Ymere's formidable size, its entrepreneurial outlook and its access to sector-specific support resources may be read as a threat. Non-profit status may constitute an additional business edge in the form of "trust attributes" (Cordes and Steuerle, 2009 p. 53) that open up 
development opportunities. Under certain sets of market conditions, could this be a further source of concern on the part of for-profit competitors?

Institutional conditions for social entrepreneurship

At a national level, Ymere's hybrid role and responsibilities are grounded in several external codes of conduct. Firstly, as a 'registered housing association' under the Central Government Housing Act 1901 (Article 70) it is bound to a government-defined social mandate (VROM:2009). The 1993 BBSH or 'housing decree' defines the relationship between housing associations and the Ministry of Housing and Spatial Planning. Within it, there is scope for profit-making through a broad range of building activities on the condition that surpluses are allocated back to the field of housing (see Articles 11, 12A and 22). Furthermore, the BBSH charges Ymere with responsibility for its own financial survival through sound policy and management (Article 21). Membership in AEDES, the 'umbrella' organisation of housing associations in the Netherlands, connects Ymere to the collective infrastructure of the non-profit sector and defines its role as a social enterprise in terms of a need to balance a long-term vision on housing needs with responsiveness to changing social values.

As a major player in the Dutch property market, Ymere is linked into the commercial real-estate community through membership in the Association of Dutch Property Developers (NEPROM), a group of 67 influential peers. Within this code, the challenges of hybrid status begin to emerge. While the government regulatory frameworks within which Ymere works encourage integration of social and commercial activities in housing markets, The NEPROM code stipulates that members must comply with European Competition Policy, which sets out requirements to keep state support for social housing out of the market. 
With the launch of the Lisbon Strategy in 2000, the EU set out to transform itself into the world's most dynamic and competitive knowledge-based economy by 2010 (Priemus, 2006). While European Competition Policy had long been superimposed over national policy environments, the Lisbon initiative advanced the institutionalization of the European Common Market and rescaled the policy environment for Dutch social housing. Based on "a razor-sharp line between public and private players” that "offers no provisions for hybrid organisations” (Priemus, 2008 p. 82), EU Competition Policy calls for targeting of state aid to the socially-disadvantaged and requires a strict separation between social and profit making activities. This is intended to prevent state-aid flowing into the commercial activities of non-profits and distorting competition. It further requires the divestment of "excessive and permanent surplus capacity" within the social housing sector (Gruis and Priemus, 2008 p. 494).

These requirements are embedded both within the Altmark Ruling, which sets out guidelines for allocation of state subsidies, and in the general provision of a 'level playing field' for competition. As Priemus points out, the concept of a 'level playing field' is open to varying interpretations and thus provides a broad basis for contestation of the role of the Dutch social housing sector (Priemus, 2008). Via an historical perspective on the two non-profit housing sectors, the next section looks at how these tensions manifest and links them to processes of change, including shifts in social-cultural and economic norms.

\section{Part Three: Australian and Dutch non-profit housing provision: an historical perspective}

Development of the Australian Policy Context

From the turn of the $20^{\text {th }}$ century, high levels of Australian homeownership have been a crucial mechanism for the transmission of culture and wealth across generations (Berry, 
1999). In recent decades, housing market conditions structured to favour investors have led to surging prices and changes in consumer expectations. While $90 \%$ of Australian adults passed through homeownership during the post-war period (Beer et al, 2007), it is now beyond the means of many. Over the past decade, low vacancy rates and skyrocketing rents have created difficult conditions for renters. The term 'housing stress', signalling housing costs in excess of either $25 \%$ or $30 \%$ of household income, is now used with increasing frequency. A recent government report identified a national shortage of 251,000 private rental dwellings in 2008 (Milligan et al, 2009).

Large-scale public housing provision began prior to World War II as a means of spatially aligning labour and industry. Over the post-war decades, private housing investment was prioritised and public housing remained a residual tenure (Beer et al, 2007). From grassroots origins, non-profit 'community housing' was formalised from the late 1970s (Bisset and Milligan, 2004) within government programs that leaned heavily on the frame of 'links between cultures. In recent years, the sector has come into favour within the context of an ideological shift away from direct government provision of social housing, and towards 'governance' of externally provided alternatives. Public housing, on the other hand has been further residualised as a 'landlord of last resort', with NSW recently ending secure tenure for new tenants. Efforts to blur boundaries between public and community housing are apparent, with shared assets used as a rationale for requiring community-housing providers to allocate from public housing waiting lists. Heavily stigmatised public housing has been repackaged as social housing, which encapsulates a range of lower-subsidy housing options.

Over recent years, decreasing housing affordability has emerged as a problem affecting not only those on low incomes, but moderate-income households and communities within which key workers have been priced out of the market. In line with Harloe's argument 
that social housing "targeted to general needs" surfaces only when a housing shortage has wider economic implications (see Harloe, 1995 p. 72), 'affordable’ rental housing has gained political popularity. While the scale of Australian 'affordable housing' falls short of Harloe's mass model, assistance is extended to moderate-income households. Presented as more of a hand-up than a charitable hand-out; 'affordable housing' rents are generally calculated as a percentage of the market-rate, rather than geared to income (Bisset and Milligan, 2004). Since 2003, state governments have designated small numbers of non-profits as 'growth providers' of such housing. In 2008, the Australian Government backed this approach with the National Rental Affordability Scheme (NRAS).

The NRAS sets out to achieve rapid, large scale outcomes in the form of 50,000 new dwellings by 2012 and a further 50,000 dwellings subject to demand. This will be done via a new set of institutional arrangements wherein support flows to for-profits in the form of an annual tax offset, while non-profits receive an annual payment. In return, dwellings must be rented to eligible tenants at $20 \%$ below market rates over a ten-year period. As a move away from the welfare orientation of the Australian social housing system, the NRAS aims to layer social housing assistance via a low-subsidy product that can be slotted back into the housing market after a ten-year social shelf-life. A further aim is to encourage "gains from trade" (Cordes and Steuerle, 2009, p. 53), within which nonprofits gain access to capital and for-profits capitalize on the non-profit 'trust' factor through association with a social cause. Positioning vital non-profit participation in the NRAS as the 'glue' bringing together developers and institutional investors to build and manage social housing, the Minister of Housing has invoked the ideal of 'hybrid vigour' stating "these kinds of partnerships or consortiums play to the strengths of the respective players" (Plibersek, 2008). She has also described "commercially sophisticated not-for- 
profit housing organisations" as "the centrepiece of the Government's reform agenda" (Plibersek, 2009).

Concerns raised by stakeholders in the NRAS highlight vulnerability to risk as the flipside of hybrid vigour. Community housing associations question whether rapid growth could compromise links to local communities (CHFA, 2007a). A property developers' submission airs concerns that the NRAS will be used to take pressure off public housing, leading to tenant default. It further suggests that with no real history of institutional investment in Australian affordable housing, progress may be slow (Property Council of Australia, 2008). This view resonates with other studies, which have emphasised non-profits' lack of experience in securing private investment and shouldering development risk (Bisset and Milligan, 2004) (CHFA, 2007a) (Milligan et al, 2009). The temporary nature of affordability requirements is also a concern. How will for-profit partners seek to maximise capital gain and rental returns when these ten-year use-requirements expire?

A further aspect of vulnerability emerged several months into the implementation of the NRAS, when the Australian Tax Office issued a sudden warning. Non-profit participants faced loss of their charitable status on the grounds that moderate-income housing provision transgresses the boundaries of a charitable mandate. While a Federal Government amendment temporarily extended the definition of charity to include the NRAS, this 'safety-net' applies only to housing projects approved within the first phase of the scheme (FAHCSIA, 2009). Pending a broader review to modernise the Australian tax system, future legal scope for non-profit housing activities remains uncertain. While the Tax Office has suggested that non-profits form subsidiaries to carry out commercial functions, some are seeking to avoid this administrative burden by having moderateincome housing recognized as a charitable pursuit (QCHC, 2008). Others have called for 
an end to charitable status as a condition of tax-exemption, on the grounds that it carries a negative stigma for tenants (see NSWFCHA, 2008).

Recent advice from the Tax Office makes a compromise seem unlikely. The ATO has warned that the social housing classification 'low-income' does not qualify a household as 'poor' and thus worthy of charitable assistance. Furthermore, it has advised that nonprofits assisting moderate-income households will place their charitable endorsements at risk, as will those assisting 'poor’ households whose situations improve (CHFA, 2009). While moderate-income housing has long been a part of the business of community housing organisations (QCHC, 2008), the frame of hybridity as a transgression has placed this practice under the spotlight. The government quest for hybrid vigour has exposed non-profits to increased levels of scrutiny.

\section{Development of the Dutch Policy Context}

In line with a Dutch constitutional provision listing "promotion of sufficient residential accommodation” as a government concern (VROM, 2009), government has been more of a promoter than a provider of housing. As far back as the early twentieth century, nongovernment religious groupings and workers' guilds provided social housing as a slumclearance initiative. Building on these corporatist roots, government officially recognized woningcorporaties (housing associations) via the Housing Act of 1901, and began a hybrid system of provision with financial and legal privileges allocated in exchange for the fulfilment of social tasks. In the post-war years, The Dutch Government subsidized the construction of large numbers of centrally-planned dwellings. Yet hybrid vigour manifested in a quantitative, rather than a qualitative form. Social housing associations during this period have been likened to government branch offices; bureaucratically controlled and disconnected from market forces and tenant-needs (AEDES, 2007). 
By the mid 1990s, Government sought a more market-oriented approach to housing provision, with stronger emphasis placed on individual responsibility. Seeking to 'cut the cord' of support for housing associations, it exchanged the value of outstanding government loans for remaining (future) property subsidy commitments (Priemus, 2008). This transition, which placed government at arm's-length, is consistent with the shift from 'government' to 'governance' that has characterised public service delivery over recent decades (Salet, 1999) (Rhodes, 1996). Within the context of this shift, housing associations have benefited to an unforeseen extent from low interest-rates and rising rent-levels and property values. Yet a variety of concessions and one-off acts of financial support still apply (AEDES, 2007). Despite their centrality to Dutch housing provision, the hybrid identity of Dutch housing associations remains controversial. Critics cite their failure to meet demand for new dwellings, whilst increasing internal expenditure. Recently, following a series of scandals over executive payments and risky investments, debate has ensued over the integrity of the hybrid form.

Since the effective rescaling of the housing market with the Lisbon Strategy of 2000, further controversy has emerged. In 2005, the EU Commissioner for Competition questioned the hybrid status of Dutch housing associations and requested tighter targeting of housing assistance (Priemus, 2008). In 2007, Dutch commercial real-estate investors filed a complaint about government support for housing associations with the European Commission, claiming a transgression of the level playing field within the property market. Housing associations’ communal guarantee fund emerged as a particular bone of contention.

Here, Kemeny's sensitivity to the strategic nature of 'structurings' of social and commercial interests in the housing market comes into play (Kemeny, 1995). Harloe’s 
argument that 'mass' forms of social housing pose a threat to core capitalist interests also resonates; but what of his claims regarding residualisation? Is the frame of hybridity as a transgression strong enough to effect radical change within the Dutch system?

Responses to the EU Commission on the part of successive Dutch governments have varied. A 2005 proposal called for a legal split of housing associations into social and market-oriented units and an explicit differentiation of their social and commercial functions (Priemus, 2006). In 2008, the present government, while emphasizing the capacity of housing associations to address housing need and social segregation, ended their exemption from corporation tax. Recently, government has advocated more robust internal governance through formal institutionalization of the social enterprise as a hybrid legal form, made accountable to local stakeholders (VROM, 2009). Stricter external regulation of housing associations has also been proposed, including a measure to curtail risk that would limit their investment in commercial projects to $33 \%$ of the total funds raised (VROM, 2009).

A recent agreement with the EU addresses tensions over the targeting of state housing assistance, with $90 \%$ of social dwellings to be allocated to households with incomes below $€ 33,000$. While AEDES cautions that the full implications of this move are not yet clear (AEDES, 2009), it could be viewed as a sign that moderate-income social housing has gained acceptance within the European economic policy environment. This would indicate divergence amongst national social housing systems rather than the uniform process of residualisation than Harloe envisaged (see Harloe, 1995 p. 546). Even so, the institution of a level playing field within the EU property market and the potential therein for interest-groups to lodge complaints constitutes a basis for further contestation of the role of housing associations (Gruis and Priemus, 2008). 


\section{Conclusions}

Born from a corporatist tradition of 'looking after your own', the Dutch social housing sector went on to function as an arm of government in the post-war years. In the mid1990s, it underwent a second transformation, emerging from a series of reforms as a network of social entrepreneurs within a housing market increasingly attuned to individualism. This unique trajectory of development has equipped non-profits with a formidable array of powers. With their hybrid form and collective infrastructure grounded in corporatism, their scale a product of 'mass' social housing provision and their role as social entrepreneurs opening up opportunities within a competitive market, contemporary Dutch housing associations embody the ideal of hybrid vigour. Yet the ambiguity of their status vis à vis EU Competition Policy and its powerful frame of transgression reveals vulnerability as a flip-side to hybrid identity.

The robust fusion of interests that characterises Dutch social housing is not apparent in Australia, where a small and developing community-housing sector is valued for the links it maintains between government, community groups and business. Housing associations, despite the emergence of a culture of social entrepreneurship, are still tied to a narrow mandate of poverty relief via their charitable status under tax-law. In positioning nonprofits as large-scale developers within the National Rental Affordability Scheme, Government seems to have overlooked the significance of this fact. While the scheme aims to build sector capacity and encourage social-entrepreneurship, legal uncertainty will not support these aspirations of 'hybrid vigour'.

The Australian Government is publicly courting the hybrid form as a magical solution to the problems of a severely dichotomised housing market. In the Netherlands, a mature non-profit housing sector has been framed as a monstrous transgression under the polarizing pressures of EU Competition Policy. In line with the theoretical expectations set out in Part One of this paper, the two cases show that while the hybrid form is valued 
from a housing policy perspective, it simultaneously transgresses the requirements of dominant economic institutions. In this light, rather than assuming a coordinated policy environment for growth and development of the non-profit sector, policy-makers must remain alert to the risks of institutional discord arising between social and commercial interests in housing markets. Where possible, potential for mediation of these interests should be explored. The table below summarises findings from the two cases.

Table 2. Dominant frames of hybridity in Australian and Dutch social housing governance

\begin{tabular}{|c|c|c|c|}
\hline & Housing Policy & Economic Law & Potential Implications \\
\hline Australia & $\begin{array}{l}\text { - } \begin{array}{l}\text { Links between } \\
\text { cultures }\end{array} \\
\text { - Hybrid vigour }\end{array}$ & Transgression & $\begin{array}{ll}\text { - } & \text { Continuing legal } \\
\text { uncertainty } \\
\text { - } & \text { Organisational change } \\
\text { (commercial } \\
\text { subsidiaries formed) } \\
\text { - } & \text { Institutional change } \\
\text { (taxation law } \\
\text { amended) }\end{array}$ \\
\hline $\begin{array}{l}\text { The } \\
\text { Netherlands }\end{array}$ & $\begin{array}{l}\text { - Hybrid vigour } \\
\text { - } \quad \text { Transgression }\end{array}$ & Transgression & $\begin{array}{ll}- & \text { Continuing legal } \\
\text { uncertainty } \\
\text { - } & \text { Organisational change } \\
\text { (new hybrid legal } \\
\text { form) } \\
\text { - } \\
\text { Institutional change } \\
\text { (new regulations in } \\
\text { housing policy) }\end{array}$ \\
\hline
\end{tabular}

Juxtaposed, Dutch and Australian cases provide an opportunity to observe the interplay between the evolving institutions that underpin housing provision. But how will current controversies impact on legal scope for non-profit activities over time? While it is not possible to predict outcomes, we may return to the theories of Harloe and Kemeny. In the wake of the 2008 financial crisis, which has revealed the rules of competition as more 
fluid than fixed, both perspectives resonate.

Following Harloe's argument; while national social housing systems vary, the "outerboundaries" to their development are now "more uniformly set" to the requirements of capitalist economic institutions (Harloe, 1995 pp. 545-6). As a result, current tensions will continue, despite a lull until the crisis ebbs. Within a converging economic institutional environment, the mature Dutch social housing sector will be viewed as a transgression and downsized. Its Australian counterpart will not be given adequate legal scope to mature and develop efficiencies of scale. As a result, the NRAS is likely to be remembered for forging links between cultures, rather than for its successful expansion of the sector.

Alternatively, following Kemeny, while “neoliberalist hubris” (Kemeny, 1995 p. xiii) over the power of social housing actors within the market will continue to influence policy; national governments retain potential to shape housing markets and to provide social assistance in different and divergent ways. Viewed thus, hybrid arrangements may lead to institutional complementarity and hybrid vigour in the form of an integrated market. A scheme like the NRAS has potential to foster sustained growth. The Dutch social housing sector's use of commercially-derived profits to support social projects need not be called into question.

Dutch and Australian cases show that legal scope for the economic activities of nonprofits does not reflect the sector's political popularity as a vehicle for social housing provision. Yet within the current context of post-crisis reform and restructuring, could change come about? Could new arrangements emerge to better reflect contemporary configurations of actors? While only time will tell, it is likely that the balance of social and commercial activities in housing markets will command greater attention over the coming years and that insights into new ways of structuring the playing field will be 
needed.

\section{References}

AEDES (2007) Dutch social housing in a nutshell, Hilversum, May 2007

AEDES (2009) http://www.aedesnet.nl

Australian Tax Office (2009) http://www.ato.gov.au/

Australian Institute of Health and Welfare (2009) Community Housing 2007-08, Commonwealth State Housing Agreement national report

Beer, Kearins, and Pieters (2007) Housing Affordability and Planning in Australia: The Challenge of Policy Under Neo-liberalism, Housing Studies,22:1,11 — 24

Bell, R. (1991) Women of Classical Mythology: A Biographical Dictionary (Oxford, University Press)

Berry, M. (1999) Unravelling the Australian Housing Solution: the Post- War Years Housing, Theory and Society; 16: 106-123.

Bisset, H. and V.Milligan (2004) Risk Management in Community Housing, Report for the National Community Housing Forum, Sydney, available at: www.nchf.org.auldownloadslRiskManagementReport.pdf 
Brandsen, T., Ribeiro, T., van Hout, E., Putters, K. (2005a) Hybridity: a Distinct Identity, Third Sector Study Group Conference of the European Group of Public Administration, Bern

Brandsen, T. van de Donk, W. and Putters, K. (2005b), Griffins or Chameleons? Hybridity as a Permanent and Inevitable Characteristic of the Third Sector, International Journal of Public Administration, 28:9,749 — 765

Burr, E (1993) The Chiron Dictionary of Greek and Roman Mythology, Chiron Publications

CECODHAS (website) (2009) Social Housing in the Netherlands, available at http://www.cecodhas.org

CHFA (Community Housing Federation of Australia) (2007a) Community Housing: Strengths, barriers to growth and partnership successes, Australian Financial Review Housing Congress

CHFA (2007b) Community housing mapping project 2005-06: report on findings. (Canberra: CHFA.)

CFHA (2009) Submission to the Henry Review of Australia's Future Tax System

Community Housing Limited (2009) http://www.chl.org.au/

The Concise Oxford Dictionary (2001) (Oxford, Oxford University Press) 
Cordes, J. and Steuerle C. (2009) Non-Profits and Business (Washington, DC, The Urban Institute Press)

Eason, C. (2007) Fabulous Creatures, Mythical Monsters, and Animal Power Symbols (Greenwood Press)

FAHCSIA (2009) (NRAS Website)

http://www.fahcsia.gov.au/sa/housing/progserv/affordability/nras/Pages/default.aspx

Gruis and Priemus (2008) European Competition Policy and National Housing Policies: International Implications of the Dutch Case, Housing Studies, 23:3,485 — 505

Harloe, M. (1995) The people's home? social rented housing in Europe and America (Oxford, Blackwell).

Heck (2009) ‘Kamer bepleit vrijheid corporaties’ NRC Handelsblad July 2, 2009

Kemeny (1995) From Public Housing to the Social Market (Routledge, London)

Kemeny, J., Kersloot, J. \& Thalmann, P. (2005) Non-profit housing influencing, leading and dominating the unitary rental market: three case studies, Housing Studies, 20, pp. 855-872.

Milligan, V, Gurran, N., Lawson, J., Phibbs, P., Phillips, R. (2009) Innovation in affordable housing in Australia, Australian Housing and Urban Research Institute 
National Shelter, inc. (2007) National Policy Platform: Australian Housing- A Fair Share? Available at:

http://www.shelter.org.au/2007\%20Policy\%20platform\%20long\%20v4.pdf

NSW Federation of Community Housing Associations Inc. (NSWFCHA) (2008)

Submission to the Inquiry into the Definition of Charities \& Related Organisations

Plibersek, T (2008), Speech to the NSW Community Housing Conference, available at http://www.tanyaplibersek.fahcsia.gov.au/internet/tanyaplibersek.nsf/content/nsw_chc_1

0sep08.htm

Plibersek, T (2009), Room for More, Speech at the Sydney Institute, available at http://www.tanyaplibersek.fahcsia.gov.au/Internet/tanyaplibersek.nsf/print/social_housin g_19mar09.htm

Priemus, H. (2006) European Policy and National Housing Systems, Journal of Housing and the Built Environment 21:271-280

Priemus, H. (2008) Real Estate Investors and Housing Associations: A Level Playing Field? The Dutch Case, European Journal of Housing Policy,8:1,81 — 96

Property Council of Australia (2008) Submission Regarding the NRAS http://www.propertyoz.com.au/Article/Resource.aspx?p=21\&submission=152

Queensland Community Housing Coalition (QCHC) (2008) Submission to the Senate Inquiry into the NRAS Bill, available at: 
http://www.aph.gov.au/SENATE/committee/clac_ctte/rental_afford_scheme/submissions/ sub09.pdf

Rhodes, R.A.W. (1996), 'The New Governance: Governing without Government', Political Studies, Vol. 64, No. 3, pp. 652-67

Salet, W. (1999) Regimes Shifts in Dutch Housing Policy, Housing Studies 14 (4)

Salet, W. and Schuiling, D. (2006), Social Entrepreneurship and the legal Challenges of hybrid non-profit organizations, GPEAN, Mexico

VROM (Ministry of Housing, Spatial Planning and the Environment) (2009) http://international.vrom.nl/

Werden, C. (2008) Community Housing A Big Business, ABC, Inside Business, available at http://www.abc.net.au/insidebusiness/content/2007/s2427283.htm

Ymere (2009) http://www.ymere.nl 